Forest Ecology

\title{
Resistance and resilience in a directly regenerating rainforest: Nicaraguan trees of the Vochysiaceae after Hurricane Joan
}

\author{
Douglas H. Boucher*,a , John H. Vandermeer ${ }^{\mathrm{b}}$, Maria Antonia Mallona ${ }^{\mathrm{c}}$, \\ Nelson Zamora ${ }^{\mathrm{d}}$, Ivette Perfecto \\ appalachian Environmental Laboratory Center for Environmental and Estuarine Studies, University of Maryland, \\ Frostburg, MD 21532, USA \\ ${ }^{b}$ Department of Biology, University of Michigan, Ann Arbor, MI 48109, USA \\ 'Departamento de Ecologia, Universidad Centroamericana, Apdo. 90, Managua, Nicaragua \\ ${ }^{\mathrm{d}}$ Departamento de Ciencias Ambientales, Universidad Nacional, Heredia, Costa Rica \\ 'School of Natural Resources, University of Michigan, Ann Arbor, MI 48109, USA
}

Accepted 14 March 1994

\begin{abstract}
Two trees of the family Vochysiaceae, Vochysia ferruginea and Qualea paraensis, were abundant in a Nicaraguan rainforest which was heavily damaged by Hurricane Joan in 1988, and both had recovered their previous densities by 1993 . However, their regeneration followed quite different paths. Vochysia suffered complete mortality of adult trees in the hurricane, but rapid growth and high survivorship of its abundant seedlings and sprouts of saplings, restored its population density (though not yet its mean diameter at breast height) and indeed led to spatial expansion. Qualea, however, showed 100\% survival of trees during the hurricane but substantial mortality in the following years. Although seedlings and sprouts of Qualea are quite rare, ingrowth is sufficient to maintain the population so far. However, vine growth on Qualea (unlike Vochysia) is substantial.

These two species are thus contrasting elements of the 'direct regeneration' which has been observed in this rainforest. The Vochysia pattern of death and recovery can be described as 'resilience', while the Qualea pattern of survival can be called 'resistance'. The regenerating Vochysia population is mostly seedlings and saplings, while that of Qualea is mostly adult trees. Depending on the pattern of regeneration, different management strategies will be appropriate for maintaining tree species subject to natural disturbances such as hurricanes and/or artificial ones such as logging.
\end{abstract}

Keywords: Disturbance; Vochysia; Qualea; Recovery

\section{Introduction}

The concept of 'direct regeneration' after disturbance to ecosystems (Boucher, 1989, 1990;

\footnotetext{
* Corresponding author at: 12908 Evanston Street, Rockville, MD 20853-3002, USA.
}

Vandermeer et al., 1990; Yih et al., 1991), in contrast to classical models of succession, suggests that the species dominant in the first years after the disturbance will be the same as the species which were dominant before the disturbance. Rather than being replaced by an early successional community dominated by pioneer 
species which are rare or absent in primary forest, under direct regeneration the specific composition of the community remains relatively unchanged, even if the disturbance causes heavy damage.

We developed the idea of direct regeneration as a description of the response of Nicaraguan rainforest to Hurricane Joan, which caused massive damage to an area of $5000 \mathrm{~km}^{2}$ on the Caribbean coast in October 1988 (Vandermeer et al., 1990; Yih et al., 1991). Despite $80 \%$ of the trees being felled or snapped off, causing substantial mortality (estimated at $23 \%$ of the trees greater than $5 \mathrm{~cm}$ diameter at breast height (DBH)), there appeared to be excellent regeneration of most tree species. Contrary to our previous expectation, typical neotropical pioneer genera such as Cecropia, Ochroma, Piper, Heliconia and Calathea were practically absent in hurricane-damaged forest, even though they were abundant in agricultural areas nearby.

However, an apparent exception to the pattern of direct regeneration was Vochysia ferruginea, a large and abundant tree at several sites in the hurricane-damaged area (Vandermeer et al., 1990; Yih et al., 1991). Although $V$. ferruginea had one of the highest densities $\left(85 \mathrm{ha}^{-1}\right)$ and largest average DBH values $(22 \mathrm{~cm})$ of the 79 tree species found, every single adult tree appeared dead when our team evaluated forest damage in February 1989, 4 months after the hurricane. Only one other of the 79 species, Vochysia hondurensis, was found with all its trees dead at this census, and it had only had one adult individual in the sampled area previous to the hurricane. (It has not reappeared and is not discussed further in this paper; subsequent mention of Vochysia refers to V.ferruginea).

Another notable aspect of Vochysia was that although no live adults were present in February 1989 , it was by far the most abundant species in the seedling layer, with a density of $94500 \mathrm{ha}^{-1}$, making up $74 \%$ of the seedlings found. Thus Vochysia stood out as unusual among the tree species of the rainforest at the February 1989 census, and appeared to be an exception to the general pattern of direct regeneration.

In contrast, the other member of the family
Vochysiaceae in the hurricane-damaged forest, Qualea paraensis, was abundant as an adult both before and after the hurricane $\left(105 \mathrm{ha}^{-1}\right.$ each time). Abundant sprouting of adults, even those which were snapped off at low heights or felled completely, was seen. However, not a single seedling of Qualea was found in the February 1989 census.

Now, 4 years after the hurricane, it is possible to compare the roles which the two abundant species of the Vochysiaceae have played in the initial phase of post-hurricane regeneration. The results, in addition to providing a test of the direct regeneration hypothesis, may be useful in managing tropical forests subject to disturbances-both natural disturbances like hurricanes and human ones like logging.

\section{Species studied}

Vochysia ferruginea, although common in the rainforest of southeastern Nicaragua, is quite variable in abundance in other parts of its range, which extends from Nicaragua to Brazil and Peru (Croat, 1978). In Costa Rica it is listed as an occasional $\left(0.1-1 \mathrm{ha}^{-1}\right)$ canopy tree of plateaux, slopes and ridges of the wet northeastern Atlantic and southern Pacific rainforests (Hartshorn and Poveda, 1983). The species has been grown successfully in plantations in northeastern Costa Rica, where it has shown excellent growth: over $5 \mathrm{~m}$ in height and $9 \mathrm{~cm}$ in DBH, with nearly $100 \%$ survivorship, after 3 years (Butterfield and Fisher, 1994).

Finegan (1992) notes that the species often dominates older secondary forest in northeastern Costa Rica, and records one site at which it had a density of 133 trees ha $^{-1}$ and a basal area of $11 \mathrm{~m}^{2} \mathrm{ha}^{-1}$. In a 25 -year-old secondary stand, nearly half of the $24 \mathrm{~m}^{2} \mathrm{ha}^{-1}$ of basal area was composed of $V$. ferruginea, with dominant trees having DBH values of $30-50 \mathrm{~cm}$ and mean annual increments of over $1 \mathrm{~cm}$. Reviewing studies 
from throughout Latin America, Finegan identified the species as one of 16 offering excellent potential for management in neotropical secondary forests. He estimates that it could be grown in Central America with rotation lengths of $30-$ 35 years.

At Barro Colorado Island, Panama it is listed among 'Pioneer species more characteristic of young forest', with 'young' here being about 100 years old (Foster and Brokaw, 1982). Croat (1978) lists it as 'occasional'; however, not a single individual of the species occurred in a 5 ha sample $(n=856)$ of trees of $60 \mathrm{~cm} \mathrm{DBH}$ or larger in this forest type (Thorington et al., 1982). Trees of the genus are described as "making their best growth on coastal plains and along waterways, forming almost pure stands on abandoned farms" (Chudnoff, 1984).

In Nicaragua, where it is known as 'zopilote' or 'botarrama' (from its habit of dropping its lower limbs ), it is used for light construction, cabinetry, toys, toothpicks and other purposes (Morales Vargas et al., 1987). The wood of the genus is relatively light to average in density and strength, and is described as useable for carpentry, plywood, furniture, interior trim and millwork and as being "suggested as a substitute for Cedrela" (Chudnoff, 1984).

Qualea paraensis, which is common at some sites in southeastern Nicaragua but absent at others, is similarly a canopy tree of slopes, ridges and plateaux in Costa Rica, where it is listed as frequent (1-10 $\left.\mathrm{ha}^{-1}\right)$ at Corcovado in the southern Pacific rainforest but very rare (less than $0.01 \mathrm{ha}^{-1}$ ) at La Selva in the northeastern Atlantic region (Hartshorn and Poveda, 1983). It is apparently not found at Barro Colorado Island (Croat, 1978; Foster and Brokaw, 1982; Thorington et al., 1982). The genus, which extends from Mexico to Peru and Brazil, has medium density and strength properties and is reported to dull saws because of silica accumulations (Chudnoff, 1984); perhaps related to this is the Nicaraguan common name of 'areno', related to 'arena', that is, sand. It is used for joinery, millwork, furniture, veneer, plywood, flooring and general construction (Chudnoff, 1984).

\section{Methods}

The majority of our demographic data come from annual censuses of $10 \mathrm{~m} \times 100 \mathrm{~m}(0.1 \mathrm{ha})$ transects in rainforest at three different sites in the hurricane-damaged region (see maps in Vandermeer et al., 1990; Yih et al., 1991 ). Four transects, two each at the Bodega and Delicias sites, were established in 1989, 4 months after the hurricane, and all trees of $5 \mathrm{~cm} \mathrm{DBH}$ or more, whether living or dead, were identified and their heights, diameters and coordinates within the transect were recorded. Their condition-standing, trunk snapped off, or completely felled-was recorded. The composition of the forest before the hurricane in 1988 was estimated using data from all trees, and the presence or absence of green leaves was used to assess which trees were alive and thus to estimate the composition of the forest in 1989. Note that all trees seen had suffered some branch damage, and all had been essentially completely defoliated by the hurricane.

Seedling densities were estimated in 1989 using ten $2 \mathrm{~m} \times 2 \mathrm{~m}$ subplots in each of the four transects, spaced systematically along the midline. All seedlings (stems $0.1-1.5 \mathrm{~m}$ in height) of tree species were counted and identified in each subplot.

In February and March of 1990 six more transects were added (two more at Delicias, one more at Bodega, and three at a new site, Fonseca ), giving a total of ten. Diameters and coordinates were recorded for all live trees of $3.2 \mathrm{~cm} \mathrm{DBH}$ or more; the diameter limit for sampling was lowered to $3.2 \mathrm{~cm}$ because it had become clear from analysis of the 1989 data that trees smaller than $5.0 \mathrm{~cm}$ were playing a major role in the forest's regrowth. Additionally, the presence of vines was noted using a four-point scale: 0 , no vines; 1 , vines on trunk but not in canopy; 2 , vines reaching canopy but not covering it; 3 , vines covering canopy.

In February-March of 1991 all $3.2 \mathrm{~cm} \mathrm{DBH}$ and up trees in the transects were recensused, and additionally all saplings in five $5 \mathrm{~m} \times 5 \mathrm{~m}$ subplots within each transect were identified and their DBH measured. In February of 1992 the tree and sapling censuses were repeated, and 
seedlings were recensused using the same methods as in 1989. Additionally, the proportion of sprouts among the ingrowth (trees entering the $3.2 \mathrm{~cm} \mathrm{DBH}$ and over category) was estimated by digging down to the roots of 206 stems, including 13 Vochysia and five Qualea, in one of the transects at the Bodega site, and classifying the stems as: sprout from standing tree, sprout from snapped tree, sprout from fallen tree, or non-sprout.

Censuses of trees only, but not of seedlings or saplings, were repeated in February of 1993. By this time agricultural clearing and settlement at the Delicias site had resulted in so much damage to three of the transects there, and to about half of the fourth, so that they had to be abandoned. Densities given for each year are calculated on the basis of only the areas actually censused. In interpreting the data, the different lower diameter limits for different years $(5.0 \mathrm{~cm}$ for 1988 $1989,3.2 \mathrm{~cm}$ for 1990-1993) should be kept in mind.

Where appropriate, the significance of differences between the two species was tested using a two-tailed $t$-test, assuming unequal variances.

\section{Results}

The basic demographic data for the two species, from before the hurricane to 4 years afterwards, are given in Table 1. Fig. 1 shows the changes in density of the two species by year, and Fig. 2 shows the year-by-year changes in diameter distributions.

This paper concentrates only on contrasts between the two Vochysiaceae. Data for many other species, and analyses of their post-hurricane regeneration, have been published elsewhere (Boucher, 1989; Boucher, 1990; Vandermeer et al., 1990; Yih et al., 1991 ), and community-level studies are continuing.

The results for the two species will be discussed separately.

\subsection{Vochysia ferruginea}

Before the hurricane, Vochysia was one of the most abundant species at the Fonseca site, where it was widely distributed within both transects censused and present in a broad range of size classes (Table 1, Fig. 2). Trees of Vochysia had a density of $85 \mathrm{ha}^{-1}$, making up $5 \%$ of the trees of $5 \mathrm{~cm} \mathrm{DBH}$ or greater found.

Four months after the hurricane, the situation was dramatically different. In contrast to nearly all other species in the forest, every single adult Vochysia was leafless and apparently dead, with $59 \%$ of them snapped off (generally at a few meters above the ground ), another $35 \%$ were completely felled, and only $6 \%$ were still standing (Table 1). Seedlings, however, were abundant, with a density of $94500 \mathrm{ha}^{-1}$ (i.e. nearly 10 $\mathrm{m}^{-2}$ ), and were present in the large majority of subplots at Bodega. Vochysia seedlings made up $74 \%$ of all seedlings found.

The regeneration of Vochysia was rapid during the following 4 years. Trees of $3.2 \mathrm{~cm} \mathrm{DBH}$ and more increased from $3 \mathrm{ha}^{-1}$ in 1990 to $19 \mathrm{ha}^{-1}$ in $1991,59 \mathrm{ha}^{-1}$ in 1992 and $125 \mathrm{ha}^{-1}$ by 1993 (Fig. 1). Seedlings decreased from 1989 to 1992 but were still abundant (over $5000 \mathrm{ha}^{-1}$ ) and widespread. Vochysia remained the most abundant species in the seedling layer, although not nearly as relatively predominant (only $17 \%$ of all seedlings) as immediately after the hurricane (Table 1).

While seedlings appeared to be the major source of Vochysia regeneration, some regeneration took place from sprouts: seven stems from five rootstocks of 13 ingrowing Vochysia sampled in 1992 were found to be sprouts. All were located at least $10 \mathrm{~m}$ away from the bases of any of the Vochysia censused in 1989, indicating that they were sprouts from saplings which had been less than $5 \mathrm{~cm} \mathrm{DBH}$ before the hurricane.

The species also regenerated at the Delicias site, where it had not been found in the 1989 censuses, and at the Fonseca site, which had not been sampled in 1989. By 1993, adults of the species had appeared in all three sites and in nine of the ten transects.

Diameter growth was rapid, averaging over 1.4 $\mathrm{cm}$ year $^{-1}$ in ingrowing Vochysia. Two ingrowing trees had reached more than $10 \mathrm{~cm} \mathrm{DBH}$ in 
Table 1

Demographic data for Vochysia ferruginea and Qualea paraensis. Significance of differences between species (two-tailed $t$-tests assuming unequal variances) is indicated as follows: ${ }^{+} P<0.10 ;{ }^{*} P<0.05 ;{ }^{* *} P<0.01 ;{ }^{* * *} P<0.001,{ }^{* * * *} P<0.0001$

\begin{tabular}{|c|c|c|}
\hline Variable & Vochysia & Qualea \\
\hline \multicolumn{3}{|l|}{ Pre-hurricane (1988) } \\
\hline Tree diameter $^{+}(\mathrm{cm})$ & $22.0(12.9)$ & $15.5(7.3)$ \\
\hline Tree density on sites where found $\left(\mathrm{ha}^{-1}\right)$ & 85 & 105 \\
\hline \multicolumn{3}{|l|}{ Immediately after the hurricane (1989) } \\
\hline Tree diameter $(\mathrm{cm})$ & - & $15.5(7.3)$ \\
\hline Tree height $(\mathrm{m})$ & - & $5.2(3.8)$ \\
\hline Tree density on sites where found $\left(\mathrm{ha}^{-1}\right)$ & 0 & 105 \\
\hline Seedling density on sites where found $\left(\mathrm{ha}^{-1}\right)$ & 94500 & 0 \\
\hline Seedling relative density $(\%)$ & 74.2 & 0 \\
\hline Seedling frequency ( $\%$ of subplots) & 90 & 0 \\
\hline \multicolumn{3}{|l|}{ Hurricane effects (1988-1989) } \\
\hline Tree mortality $(\%)$ & 100 & 0 \\
\hline Trees fallen $(\%)$ & 35.3 & 14.3 \\
\hline Trees snapped off $(\%)$ & 58.8 & 81.0 \\
\hline Trees standing (\%) & 5.9 & 4.8 \\
\hline \multicolumn{3}{|l|}{ Regeneration (1992) } \\
\hline Seedling density on sites where found $\left(\mathrm{ha}^{-1}\right)$ & 5028 & 333 \\
\hline Seedling relative density $(\%)$ & 17.1 & 0.4 \\
\hline Sapling density on sites where found $\left(\mathrm{ha}^{-1}\right)$ & 1040 & 0 \\
\hline Sapling relative density $(\%)$ & 9.8 & 0 \\
\hline \multicolumn{3}{|l|}{ After 4 years (1993) } \\
\hline Tree diameter ${ }^{* * * *}(\mathrm{~cm})$ & $4.3(2.5)$ & $17.6(8.7)$ \\
\hline Tree density on sites where found $\left(\mathrm{ha}^{-1}\right)$ & 124.6 & 133.3 \\
\hline Tree diameter, using 1989 sites and sizes only** $(\mathrm{cm})$ & $7.3(1.6)$ & $18.9(7.3)$ \\
\hline Tree density, 1989 sites and sizes only $\left(\mathrm{ha}^{-1}\right)$ & 53.3 & 123.3 \\
\hline Tree frequency ( $\%$ of transects) & 90 & 20 \\
\hline Vine cover ${ }^{* * * *}$ (score on $0-3$ scale) & $0.6(0.8)$ & $1.6(1.0)$ \\
\hline \multicolumn{3}{|l|}{ Change (1990-1993) } \\
\hline Tree mortality $\left(\%\right.$ year $\left.^{-1}\right)$ & 0.3 & 4.2 \\
\hline Tree ingrowth $\left(\%\right.$ year $\left.{ }^{-1}\right)$ & 1044.4 & 4.8 \\
\hline Tree density change $\left(\%\right.$ year $\left.^{-1}\right)$ & 1033.3 & 0.0 \\
\hline Growth $^{* * * *}\left(\mathrm{~cm} \mathrm{DBH} \mathrm{year}^{-1}\right)$ & $1.42(0.75)$ & $0.27(0.97)$ \\
\hline
\end{tabular}

Data for tree diameter, height, growth and vine cover are means (standard deviation in parentheses).

just 4 years of growth, although more than $60 \%$ remained under $5 \mathrm{~cm}$ DBH in 1993. Thus, although the density of Vochysia trees was approaching its pre-hurricane level in 4 years, its mean size remained considerably less (Fig. 2).

Mortality among trees of $3.2 \mathrm{~cm} \mathrm{DBH}$ and more was very low-only $0.3 \%$ year $^{-1}$ between 1990 and 1993. Combined with the rapid rate of ingrowth, this resulted in a more than ten-fold increase $(1033 \%)$ in the population density of trees $3.2 \mathrm{~cm} \mathrm{DBH}$ and over in just 3 years. Only $39 \%$ of the trees censused in 1993 had any vines growing on them (mean score was 0.55 on the 0 3 scale ).

\subsection{Qualea paraensis}

The behavior of the Qualea population has been quite different. The species was even more abundant than Vochysia before the hurricane ( $105 \mathrm{ha}^{-1}, 6 \%$ relative density), although its mean diameter was somewhat smaller $(15 \mathrm{~cm}$, vs. $22 \mathrm{~cm}$ for Vochysia). Although nearly all adult Qualea above $5 \mathrm{~cm} \mathrm{DBH}$ were damaged (81\% snapped off and $14 \%$ completely felled), not a single individual died; all had leaves in February 1989. Mean height of the trees was over $5 \mathrm{~m}$. However, not a single seedling of Qualea was found in 1989, and very few appeared in the 1992 
(a)

vochysia

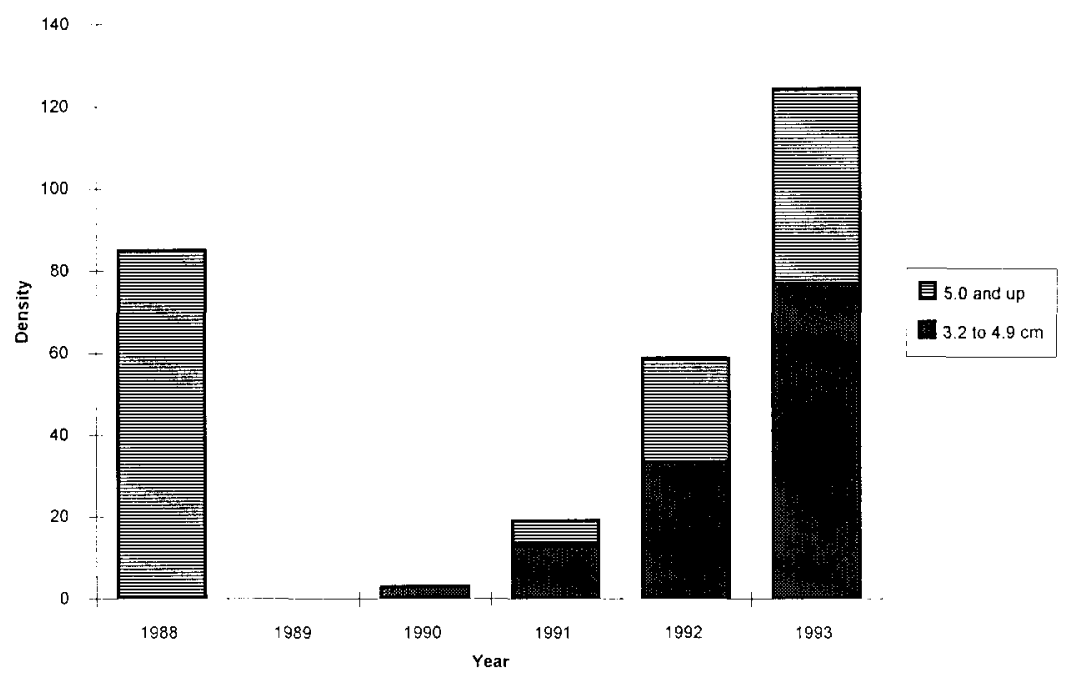

(b)

Qualea

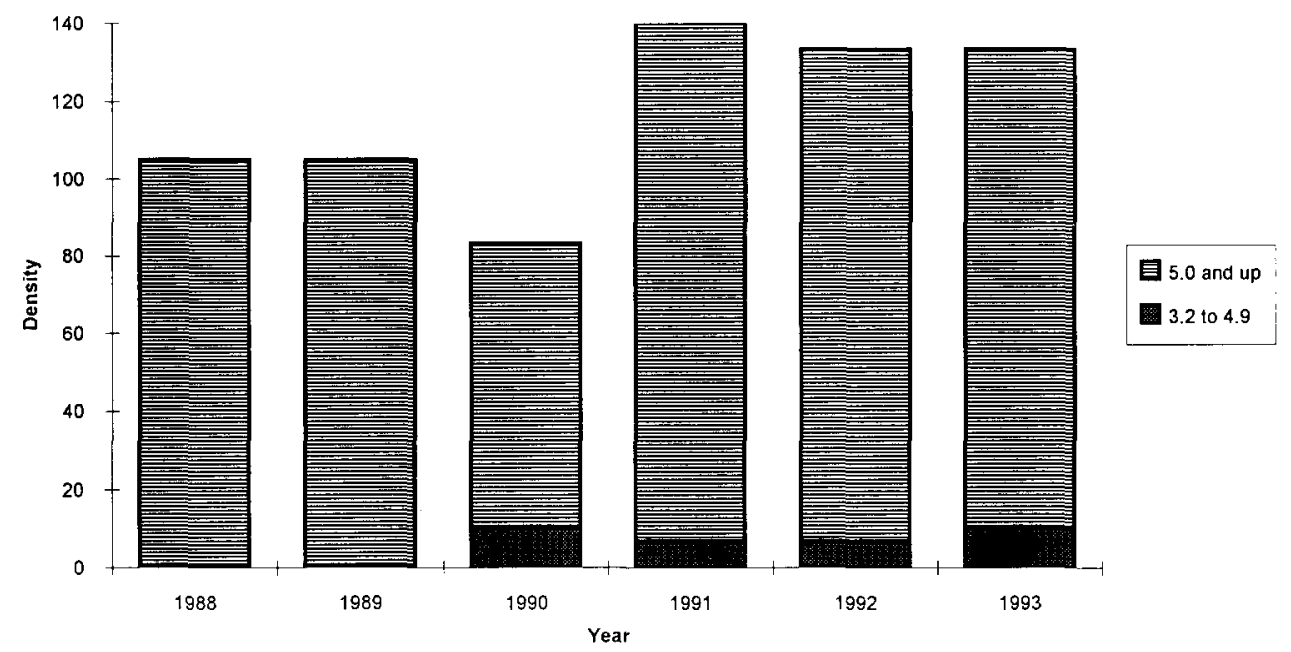

Fig. 1. Density $\left(\mathrm{ha}^{-1}\right)$ of trees of different size categories $(3.2-4.9 \mathrm{~cm} \mathrm{DBH}, 5.0+\mathrm{cm} \mathrm{DBH})$ by year at sites where the species was found: (a) Vochysia; (b) Qualea.

census ( $333 \mathrm{ha}^{-1}, 0.4 \%$ of all seedlings ). No saplings at all were found in the 1992 sample (Table 1).

Diameter growth of Qualea was slow, averaging less than $0.3 \mathrm{~cm}_{\text {year }}{ }^{-1}$ between 1990 and 1993 (Table 1). The diameter distribution of the species hardly changed at all in this period (Fig. 2 ). No change in spatial distribution was seen, so that by 1993 the species still was found at only one of the three sites and in only two of the ten transects.

Ingrowth of Qualea to the $3.2 \mathrm{~cm} \mathrm{DBH}$ and over size has been just matched by mortality ( $4.2 \%$ year $^{-1}$ mortality, $4.8 \%$ year $^{-1}$ ingrowth from 1990 to 1993 ), so that the density has remained the same over this period. Eighty-two 
(a)

vochysia

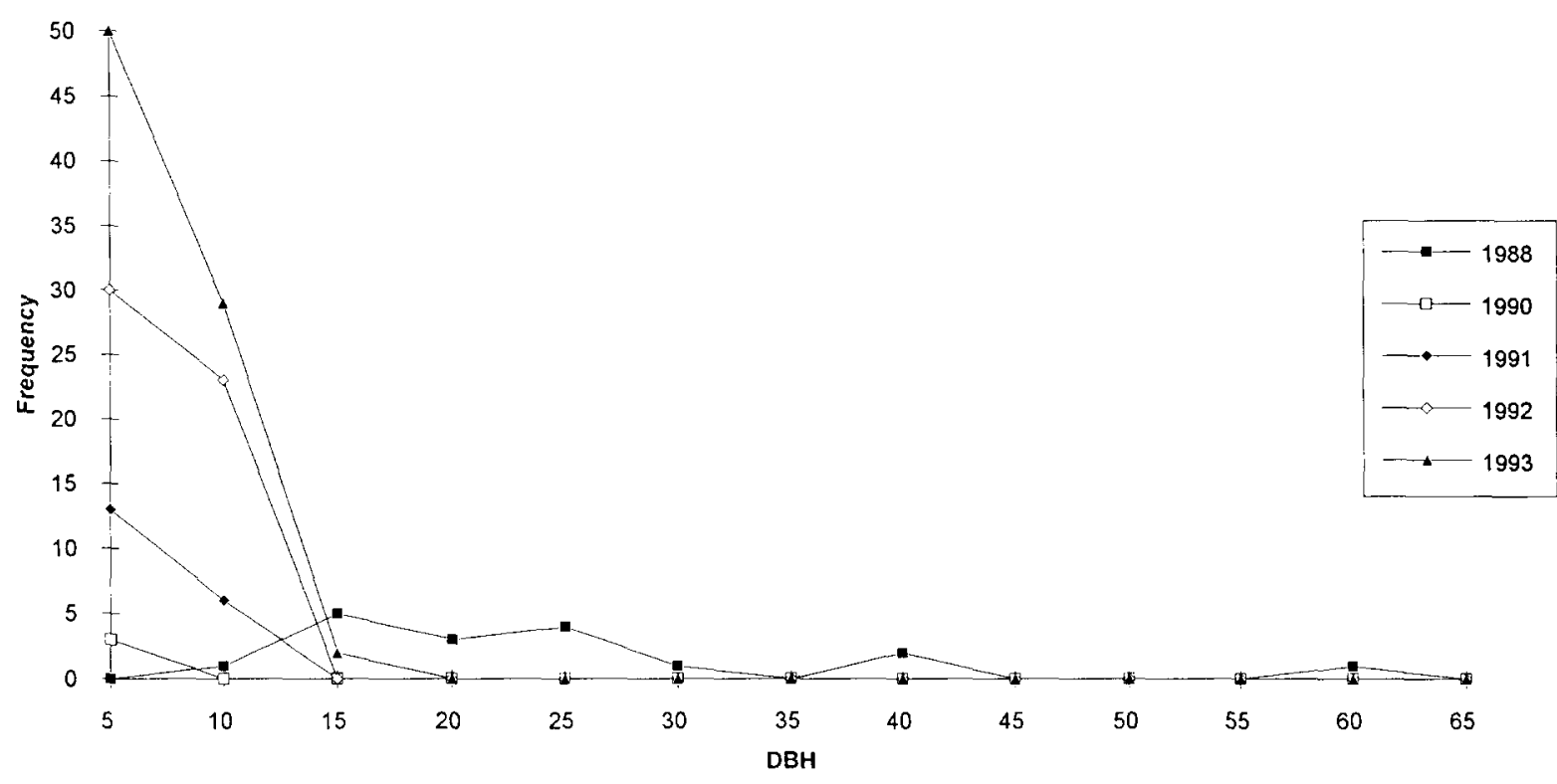

(b)

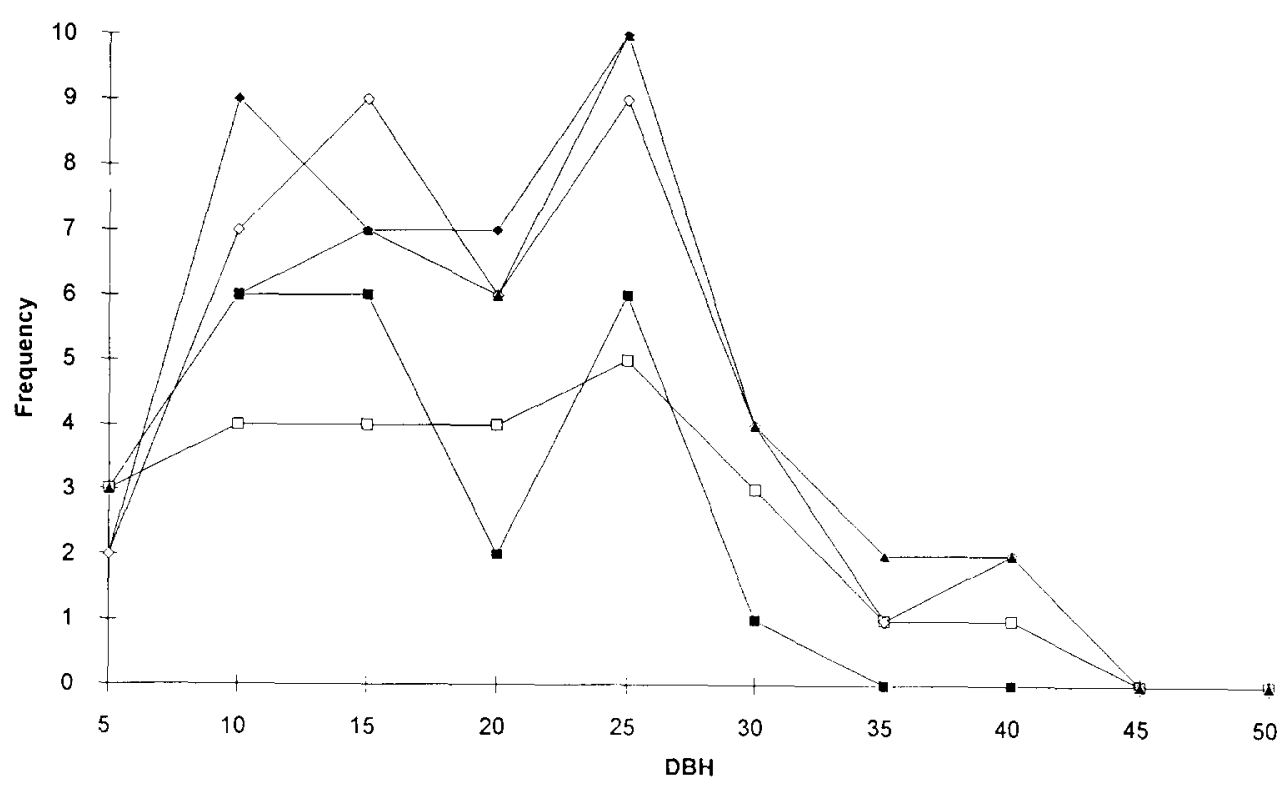

Fig. 2. DBH distribution of trees (over $5.0 \mathrm{~cm} \mathrm{DBH}$ for $1988-1989$, over $3.2 \mathrm{~cm}$ DBH subsequently) by year: (a) Vochysia; (b) Qualea. 
percent of the trees censused in 1993 have some vine growth, with a mean score of 1.6.

\section{Discussion}

While both Vochysia and Qualea have attained their pre-hurricane abundances, and are important elements of the direct regeneration of the forest (Vandermeer et al., 1990; Yih et al., 1991 ), they have reached the same point by very different paths. Their differences correspond in general to Clark's (1991) distinction between Type A species, in which adults are killed by the disturbance and the population regenerates from juveniles, and Type B species, in which most adults survive the disturbance.

Vochysia originally appeared to die out completely, despite its previous abundance, and seemed to be an exception to the general trend of resprouting and maintenance of primary forest species in the post-hurricane community. However, the results presented here show that it has recovered well, and indeed appears to be on its way to an even greater density (albeit with a much smaller mean diameter) than before the hurricane (Table 1, Fig. 1(a)). This recovery has come both from seedlings and from resprouting of saplings (though not of large trees), and has been marked by a low post-hurricane mortality rate, a rapid rate of $\mathrm{DBH}$ growth, and expansion to sites and transects where it had not been found before.

Qualea has shown the opposite pattern: low mortality in the hurricane but high mortality since then, very few seedlings and saplings, slow DBH growth, and no spatial spread. Its pre-hurricane abundance (the highest of any species at the Bodega site) has been maintained by excellent resistance to mortality in the storm, despite heavy damage $(81 \%$ of trees snapped off, $14 \%$ completely felled), and by a balance of ingrowth and mortality rates since then.

Both kinds of response have been sufficient to restore the species to their pre-hurricane densities within 4 years. However, each has particular advantages and disadvantages in terms of the likelihood of the species' maintaining itself in the long term.

The Vochysia pattern of death and recovery corresponds to the Type A species described by Clark (1991). It has allowed rapid regeneration and, indeed, spread, and takes advantage of the high light levels present in the early post-hurricane years. It also appears to allow the species to outgrow vines. However, it makes the population's survival extremely dependent on the fate of its seedlings. In this case they seem to have done very well, but in other circumstances they might suffer high mortality, either during the hurricane (e.g. from flooding) or in the years immediately afterwards (e.g. from disease or herbivory). Furthermore, the small size of most Vochysia trees makes them vulnerable to being overtopped and shaded out by other species in future years, although there is no sign of this so far in either the DBH growth rates (Table 1) or our observations of spatial relationships in the field.

The Qualea pattern of survival, which corresponds to Clark's (1991) Type B, maintains the abundance of the adult population as well as its position as one of the taller species in the forest canopy, which is now much lower and much more patchy than before the hurricane (now about $5 \mathrm{~m}$ high, versus perhaps $30-35 \mathrm{~m}$ high before). The species' continued survival has not been dependent on the survival and regrowth of seedlings, and the trees present after 4 years seem unlikely to be overtopped in the near future despite their slow rate of DBH growth. However, the considerable rate of mortality since 1990 , averaging over $4 \%$ year $^{-1}$, must be balanced by ingrowth from a relatively small pool of seedlings and saplings if the species is to maintain its density in the long term. The apparent lack of a strong growth response to post-hurricane conditions may also eventually lead to its falling behind in competition for light as other species recover. The substantial vine growth on most trees may be part of the reason for slow growth, and could potentially become a serious problem in future years.

The patterns shown by these two species seem to represent end points on a continuum of re- 
sponses which together have led to the direct regeneration of the forest. Other species which continue to be abundant in the forest after 4 years (e.g. Cupania glabra) seem to be intermediate between these extremes, with a mixture of both surviving adults and fast-growing seedlings and sprouts.

The two patterns also correspond to the theoretical distinction between resistance and resilience (Liddle, 1975; DeAngelis, 1992). Resistant systems show little change in the values of their state variables despite strong disturbances. Resilient systems, however, may show substantial changes, but return rapidly to their pre-disturbance values. In these terms, Qualea is an example of a resistant population, while Vochysia is an example of a resilient one.

The continuum of responses to disturbance, with resistance at one end and resilience at the other, can be applied to a wide variety of systems (e.g. human impact on trails; Boucher et al., 1991 ). It also has practical implications for forest management, both in the conservation of tree species subject to major disturbances and in the choices of techniques for sustained-yield exploitation of resources such as timber and fruit. Maintaining a viable population of trees clearly requires different kinds of management depending on whether the post-disturbance population is mostly adults, as with Qualea, or seedlings and saplings, as with Vochysia. For populations such as Qualea to maintain themselves, adult mortality after the disturbance must be kept low. For species such as Vochysia to continue to survive, however, establishment and growth of seedlings and small sprouts must be high after the disturbance in order for the population to recover.

Logging techniques for resilient species such as Vochysia may thus be able to extract most of the adult trees of the population, and make the canopy considerably more open, without endangering the survival of the species-but only if care is taken to be sure that seedlings are abundant and have good conditions for establishment and growth. Finegan (1992) shows how $V$. ferruginea and similar species (called long-lived intolerants, late-secondary species, light hardwoods, small-gap specialists or big pioneers by various authors ) can form the basis of productive management systems based on secondary forests. With resistant species such as Qualea, however, selection techniques which take a small proportion of the adult trees and do not create conditions favoring the growth of vines or pioneer trees, are recommended.

\section{Acknowledgments}

We thank the Center for Studies and Documentation of the Atlantic Coast (CIDCA) and the School of Ecology and Natural Resources (ECORENA), both of the Central American University (UCA), for their support of all our work and Marg Reeves, Inigo de la Cerda, Linda Roth, Ernesto Leymus and the students of the 1990-1993 UCA-University of Michigan Rainforest Dynamics courses for their hard work in the field. This study was supported by National Science Foundation grant DSR 891768 to John H. Vandermeer. This is Contribution Number 2263 from the Appalachian Environmental Laboratory, Center for Environmental and Estuarine Studies, University of Maryland.

\section{References}

Boucher, D.H., 1989. When the hurricane hit the rainforest. Biol. Digest, 16(4): 11-18.

Boucher, D.H., 1990. Growing back after hurricanes. BioScience, 40:163-166.

Boucher, D.H., Aviles, J., Chepote, R., Dominguez Gil, O.E. and Vilchez, B., 1991. Recovery of trailside vegetation from trampling in a tropical rainforest. Environ. Manage., 15:257-262.

Butterfield, R.P. and Fisher, R.F., 1994. Untapped potential: native species for reforestation. J. For., 92: 37-43.

Chudnoff, M., 1984. Tropical timbers of the world. Agriculture Handbook 607. USDA Forest Service, Washington, DC, $464 \mathrm{pp}$.

Clark, J.S., 1991. Disturbance and tree life history on the shifting mosaic landscape. Ecology, 72:1102-1118.

Croat, T., 1978. Flora of Barro Colorado Island. Stanford University Press, Stanford, CA, 943 pp.

DeAngelis, D.L., 1992. Dynamics of Nutrient Cycling and Food Webs. Chapman and Hall, New York, 270 pp.

Finegan, B., 1992. The management potential of neotropical secondary lowland rain forest. For. Ecol. Manage., 47:295321. 
Foster, R.B. and Brokaw, N.V.L., 1982. Structure and history of the vegetation of Barro Colorado Island. In: E.G. Leigh, Jr., A.S. Rand and D.M. Windsor (Editors), The Ecology of a Tropical Forest: Seasonal Rhythms and Long-term Changes. Smithsonian Institution Press, Washington, DC, pp. 67-81.

Hartshorn, G.S. and Poveda, L.J., 1983. Checklist of trees. In: D.H. Janzen (Editor), Costa Rican Natural History. University of Chicago Press, Chicago, IL, pp. 158-183.

Liddle, M.J., 1975. A theoretical relationship between the primary productivity of vegetation and its ability to tolerate trampling. Biol. Conserv., 8:251-255.

Morales Vargas, A., Castro Gutierrez, M. and Avendano Medrano, P., 1987. Manual de Identificacion Macroscopica de Cincuenta Especies Maderables Nicaraguenses. IRENA/Interforest/Swedforest, Managua, Nicaragua.
Thorington, Jr., R.W., Tannenbaum, B., Tarak, A. and Rudran, R., 1982. Distribution of trees on Barro Colorado Island: a five hectare sample. In: E.G. Leigh, Jr., A.S. Rand and D.M. Windsor (Editors), The Ecology of a Tropical Forest: Seasonal Rhythms and Long-term Changes. Smithsonian Institution Press, Washington, DC, pp. 8394.

Vandermeer, J., Zamora, N., Yih, K. and Boucher, D., 1990. Regeneración inicial en una selva tropical de la costa caribea de Nicaragua despues de los efectos destructivos del huracan Juana. Rev. Biol. Trop., 38:347-359.

Yih, K., Boucher, D.H., Vandermeer, J.H. and Zamora, N., 1991. Recovery of the rain forest of southeastern Nicaragua after destruction by Hurricane Joan. Biotropica, 23:106-113. 